\title{
A COPD self management programme reduced hospital use and improved health status
}

\author{
Bourbeau J,Julien M, Maltais F, et al. Reduction of hospital utilization in patients with chronic obstructive pulmonary
} disease: a disease-specific self-management intervention. Arch Intern Med 2003;163:585-91.

\section{QUESTION: In patients with chronic obstructive pulmonary disease (COPD), does a COPD specific self management programme reduce hospital use and improve health status more than usual care?}

\section{Design}

Randomised (allocation concealed), blinded \{data collectors and data analysts $\}^{*}$, controlled trial with 12 months of follow up.

\section{Setting}

7 hospitals in 3 cities in Quebec, Canada.

\section{Patients}

191 patients $\geq 50$ years of age (mean age $70 \mathrm{y}, 55 \%$ men) who had stable COPD (respiratory symptoms and medication unchanged for $\geq 4 \mathrm{wks}$ ); were current or previous smokers; had an FEV $125-70 \%$ of predicted and an $\mathrm{FEV}_{1}$ forced vital capacity ratio $<70 \%$; no previous asthma, left congestive heart failure, terminal disease, dementia, or uncontrolled psychiatric illness; had not been in a respiratory rehabilitation programme in the previous year; and had no long term care facility stays. $86 \%$ of patients completed the 12 month assessment.

\section{Intervention}

Patients were stratified by centre. 96 patients were allocated to a self management programme ("Living Well with COPD," Boehringer Ingelheim Canada) delivered by case managers (nurses, respiratory therapists, and a physiotherapist) for 1 hour per week in the patient's home for 7-8 weeks. The programme included 7 educational modules on COPD, a customised action plan for acute exacerbations linked with therapeutic actions (including a prescription for an antibiotic and oral corticosteroid to be initiated promptly for exacerbations characterised by specific symptoms), case manager availability by telephone, and exercise programme instruction (warm up and stretching, muscle, and cardiovascular exercises to be done $\geq 3$ times/wk for $30-45 \mathrm{~min} /$ session). 95 patients were allocated to usual care (management by treating physician, free healthcare services, and drug benefit plan)

\section{Main outcome measures}

Hospital admission (acute hospital stay of any duration, day hospital stay $\geq 8 \mathrm{~h}$ for 2 consecutive $\mathrm{d}$, or emergency department [ED] visit requiring $\geq 24 \mathrm{~h}$ of care). Secondary outcomes included unscheduled physician and ED visits.

\section{Main results}

Analysis was by intention to treat. 299 acute exacerbations occurred in the self management group and 362 in the usual care group. Patients in the self management group had fewer admissions for acute exacerbations (71 v 118 admissions, $\mathrm{p}=0.01$ ), fewer $\mathrm{ED}$ visits for acute exacerbations (95 v 161 visits, $\mathrm{p}=0.02$ ), and fewer unscheduled visits to their family physician (46 $v 112$ visits, $\mathrm{p}=0.003$ ). Fewer patients in the self management group had $\geq 1$ admission for acute exacerbation or $\geq 1$ $\mathrm{ED}$ visit for acute exacerbation (table).

\section{Conclusion}

A COPD specific self management programme reduced hospital use and improved health status more than usual care.

*Information provided by author. du Québec.

For correspondence: Dr J Bourbeau, Montreal Chest Institute of the Royal Victoria Hospital, McGill University,

Montreal, Quebec,

Canada.

jean.bourbeau@mcgill.ca

A modified version of this abstract appears in ACP Journal Club.

Disease specific self management $v$ usual care for acute exacerbations (AEs) of chronic obstructive pulmonary diseaset

\begin{tabular}{lllll}
\hline $\begin{array}{l}\text { Outcomes at 12 } \\
\text { months }\end{array}$ & $\begin{array}{l}\text { Self } \\
\text { management }\end{array}$ & Usual care & RRR (95\% CI) & NNT (CI) \\
$\begin{array}{l}\text { Patients with } \geq 1 \\
\text { hospital }\end{array}$ & $32 \%$ & $51 \%$ & $36 \%(10$ to 55$)$ & 6 (4 to 24$)$ \\
$\begin{array}{l}\text { admission for AEs } \\
\text { Patients with } \geq 1\end{array}$ & $41 \%$ & $63 \%$ & $36 \%(15$ to 52$)$ & 5 (3 to 12) \\
$\begin{array}{l}\text { emergency } \\
\text { department visits } \\
\text { for AEs }\end{array}$ & & & \\
\hline †Abbreviations defined in glossary; RRR, NNT, and Cl calculated from data in article. &
\end{tabular}

\section{COMMENTARY}

Current approaches to self management education for COPD in clinical practice are diverse, varying from providing printed materials to individualised teaching sessions to convey information, and group workshops to teach patients specific skills. The study by Bourbeau $e t$ al assessed a multifaceted self management intervention, which comprised individual education, skills training, self help workbooks, and supportive telephone calls. Although the self management intervention did not improve lung function or exercise capacity, exacerbations, hospital admissions, and use of other healthcare facilities were reduced.

The needs of patients with COPD and their families are recognised in the guidelines of the Global Initiative for Chronic Obstructive Lung Disease, ${ }^{1}$ which highlight the importance of patients understanding the nature of the disease, risk factors for progression, and the role of healthcare providers in achieving optimal management and health outcomes. The guidelines also suggest that education should be tailored to the needs and environment of individual patients.

A recent meta-analysis concluded that insufficient data were available to recommend self management education for patients with COPD. ${ }^{2}$ The review identified a limited number of studies, which included a broad spectrum of interventions and outcomes.

It would be useful to compare this self management programme with disease specific counselling to determine whether the education or support components were responsible for the beneficial effects. Also, it would be useful to assess the effects on behaviours such as smoking cessation and compliance with drug therapy, as these could help explain reasons underlying improvements in health status.

Although this intervention may save money by reducing exacerbations and use of healthcare resources, improvements in health status that are important to patients should also be considered.

Haleema Shakur, RGN, MSc Trial Manager London School of Hygiene and Tropical Medicine London, UK

1 Pauwels RA, Buist AS, Calverley PM, et al. Global strategy for the diagnosis, management, and prevention of chronic obstructive pulmonary disease. NHLBI/WHO Global Initiative and prevention of chronic obstrive pulmonary disease. NHLBI/WHO Global lnitiative Med 2001;163:1256-76. Monninkhof EM, van der Valk PD, van der Palen J, et al. Self-management education for chronic obstructive pulmonary disease. Cochrane Database Syst Rev 2003;(1):CD002990. 